\title{
Female sterilisation: is it what women really want or are alternative contraceptive methods acceptable?
}

\author{
Alison Mattinson, Diana Mansour
}

\section{Abstract}

Objective An initial audit was conducted in 2001 to monitor all women referred for female sterilisation. This reaudit in 2003 set out to investigate those women who initially chose alternative reversible contraception and ascertain whether they were still using that method or if they or their partner had requested sterilisation.

Methods A telephone survey of general practitioners was conducted, 2 years after an initial sterilisation counselling appointment, of those women who initially had chosen alternative, reversible forms of contraception.

Results Information regarding current contraception was obtained for $44(85 \%)$ of the cohort of 52 women. Three women and five of their partners (15.4\%) had been sterilised in the intervening 2 years. Two women had undergone hysterectomy for gynaecological reasons. Thirty-four $(65.4 \%)$ women were using reversible contraceptive methods and $31(59.6 \%)$ were still using the same contraceptive method chosen at the sterilisation counselling appointment. Information was not available for eight (15.4\%) women.

Conclusions Female sterilisation counselling within a contraception and sexual health service successfully offers a full range of contraceptive alternatives. This small audit indicates that at least two-thirds of women who choose one of these alternatives will still be using this method 2 years later. Although the number of women in this audit is small, we suggest that this change in service delivery has contributed to a decline in female sterilisation within the district and has led to an increased use of effective, reversible hormonal contraception within the community and hospital services.

J Fam Plann Reprod Health Care 2006; 32(3): 181-183 (Accepted 4 January 2006)

Key message points
- Approximately $60 \%$ of women who declined sterilisation
following counselling are still using their chosen
alternative, reversible, contraceptive method 2 years later.
- Only $5.8 \%$ of women were sterilised in the 2 years after
initial counselling.
- Discussion of alternative, reversible methods of
contraception at the sterilisation counselling appointment
may help to reduce the number of women undergoing this
procedure.

Newcastle-upon-Tyne Contraception and Sexual Health Services, Graingerville Clinic, Newcastle General Hospital, Newcastle-upon-Tyne, UK

Alison Mattinson, MRCGP, FFFP, Associate Specialist

Diana Mansour, FRCOG, FFFP, Consultant in Community

Gynaecology and Reproductive Health Care

Correspondence to: Dr Diana Mansour, Newcastle-upon-Tyne Contraception and Sexual Health Services, Graingerville Clinic, Newcastle General Hospital, Westgate Road, Newcastle-uponTyne NE4 6BE, UK.

E-mail: diana.mansour@newcastle-pct.nhs.uk

\section{Introduction}

In 2001, an audit was carried out to monitor all women referred by primary and secondary care for female sterilisation. ${ }^{1}$ All patients were counselled by health professionals with a special interest in contraception in a family planning setting. Between January and June 2001, 226 women had appointments for female sterilisation counselling. Only $153(68 \%)$ women attended their appointments. Of those, $101(66 \%)$ chose to be sterilised after counselling and $52(34 \%)$ chose other methods of contraception.

This follow-up survey looked at the 52 women who chose not to be sterilised to assess whether they were still using their chosen form of contraception 2 years later or had subsequently undergone sterilisation.

\section{Methods}

Current up-to-date information concerning the contraceptive method used by the previous audit cohort was obtained by telephoning the woman's general practice. All practices had agreed to this repeat audit process and were notified in advance by letter. As the number of women in this survey was small, no statistical tests were undertaken.

\section{Results}

Information regarding current contraception was obtained for 44/52 (85\%) women. There was no recent contraceptive information recorded in the patient notes for eight (15\%) of these women. Perhaps this is because they were not sexually active or they were successfully using a longacting contraceptive method/changed to another method and required no medical assistance.

\section{Contraceptive methods used at the time of sterilisation} counselling in 2001

At the sterilisation counselling appointment in 2001 these 52 women were mostly using oral contraception or condoms (Figure 1).

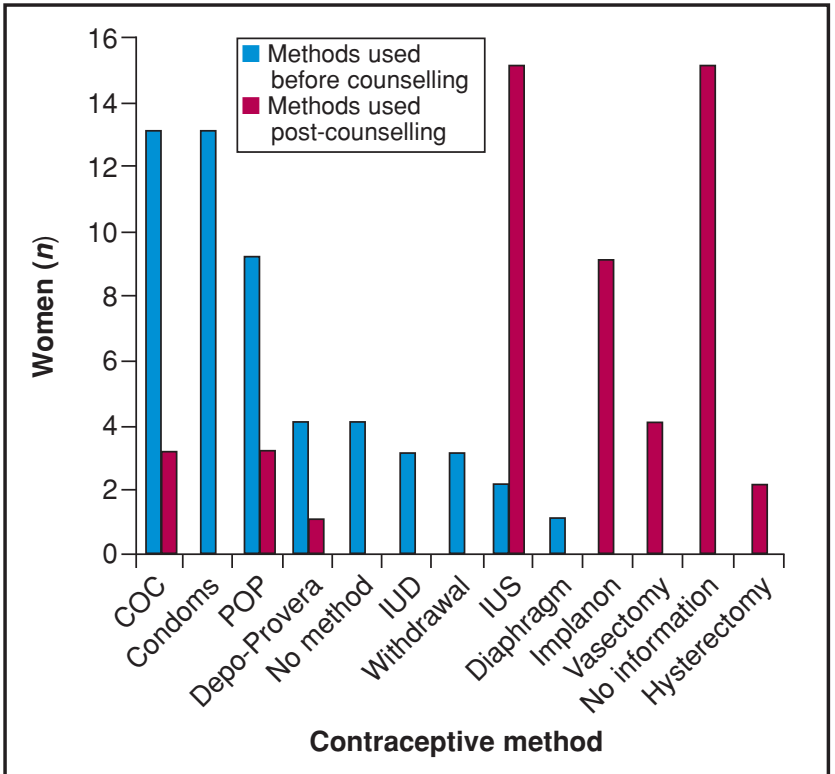

Figure 1 Contraceptive methods used before and after female sterilisation counselling in 2001. COC, combined oral contraceptive pill; IUD, intrauterine device; IUS, intrauterine system; POP, progestogen-only pill 


\section{SHORT COMMUNICATION}

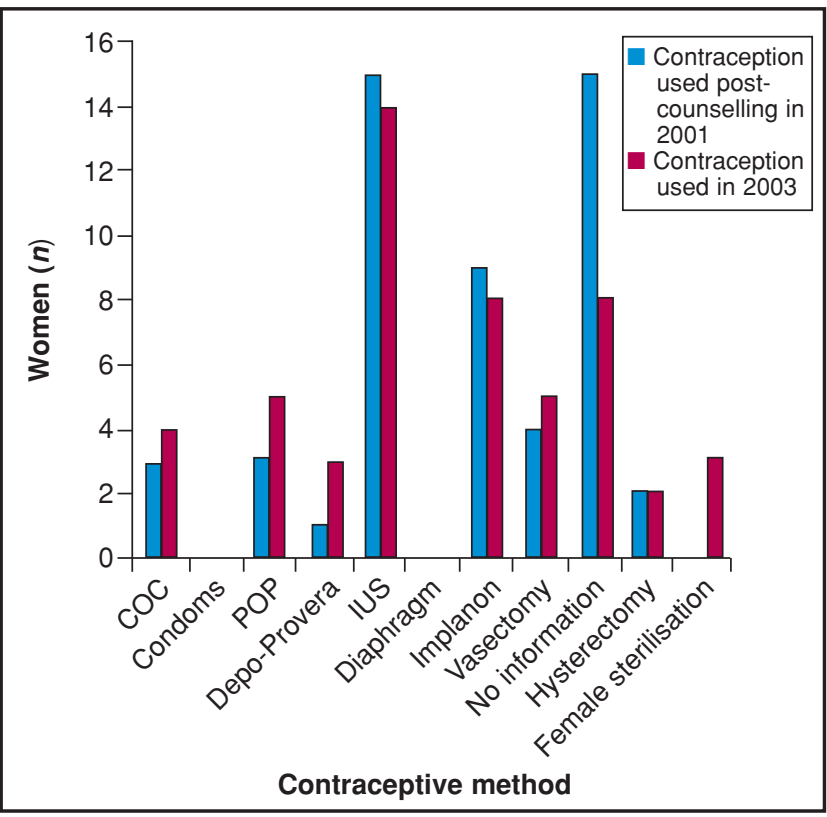

Figure 2 Contraceptive methods used after female sterilisation counselling in 2001 and 2003. COC, combined oral contraceptive pill; IUS, intrauterine system; POP, progestogen-only pill

\section{Alternative methods of contraception used by this cohort} following sterilisation counselling in 2001

Following counselling in 2001, a variety of contraceptive methods were chosen (Figure 1) with a high proportion requesting a long-acting, reversible preparation. In the next 2 years, two $(3.8 \%)$ women underwent hysterectomies for menorrhagia. Some women remained undecided following initial counselling and others, who chose or who expressed an interest in alternatives such as the intrauterine system (IUS), contraceptive implant or vasectomy, failed to attend appropriate clinic appointments. Information on subsequent contraceptive choice did become available for some of these 15 women in the survey carried out in 2003.

\section{Methods of contraception being used in 2003 (2 years} after sterilisation counselling)

Two years after the initial audit a further survey was carried out on the cohort of 52 women (Figure 2).

\section{Female sterilisation}

Only three (5.8\%) women had been sterilised in this 2-year interval. One woman had used an IUS for 15 months then requested its removal. Subsequently she became pregnant, underwent a termination of pregnancy and was sterilised 4 months following this procedure. The second woman failed to keep her appointment for IUS insertion and was sterilised 6 months later. The third woman had a contraceptive implant inserted and this was removed at the time of female sterilisation almost 2 years later.

\section{IUS}

The IUS was still the most popular method being used by $14(27 \%)$ of this cohort. Thirteen of these women had the IUS fitted in 2001 and one couple decided not to proceed with a vasectomy but to use the IUS instead. Two women who had an IUS inserted in 2001 requested their removal, one at the time of female sterilisation and the second after her partner had undergone a vasectomy.

\section{Implant}

Eight women were using a contraceptive implant. Seven of them chose it and had it inserted in 2001 and one was a nonattender for IUS insertion who subsequently had an implant inserted elsewhere. Two women had their implants removed, one of these being 2 years later when undergoing sterilisation.

\section{Oral contraception}

Six women originally chose to continue taking oral contraception. Two years later four were taking a combined oral contraceptive pill (COC) and five a progestogen-only pill (POP). The extra users were women who were undecided previously, had failed to attend for an implant insertion and who had failed to attend for vasectomy counselling. One COC user was now using depot medroxyprogesterone acetate (DMPA) and the original DMPA user was now using the POP.

\section{Vasectomy}

Five couples were using vasectomy as their method of contraception in 2003. Four of these had the procedure performed in 2001 after counselling. One woman had chosen an IUS but had this removed after her partner had undergone a vasectomy.

\section{DMPA injection}

Three women were using DMPA. None had chosen it after female sterilisation counselling in 2001. One had originally opted to continue the COC and two women were undecided. The woman who chose DMPA following sterilisation counselling in 2001 was now using a POP.

\section{Discussion}

Our initial audit in 2001 showed that only $61 \%$ of women went ahead with the sterilisation procedure after counselling. In 2001, 52 women chose alternative forms of contraception. Two years later in 2003 just three (5.8\%) women and five $(9.6 \%)$ of their partners had subsequently undergone sterilisation, with 34 (65.4\%) women still using reversible contraceptive methods. Thirty-one $(59.6 \%)$ of the 52 women were still using the same contraceptive method chosen at the sterilisation counselling appointment, with 25 continuing to use a long-acting reversible method. Although this is a small cohort, our findings suggest that counselling about all the contraceptive options helps women make an informed choice and enables them to choose a method that best suits their needs. Further research is required involving a larger cohort to fully evaluate the success of sterilisation counselling in community and more traditional hospital settings.

This small follow-up audit confirms the findings of our initial work ${ }^{1}$ that many women referred for female

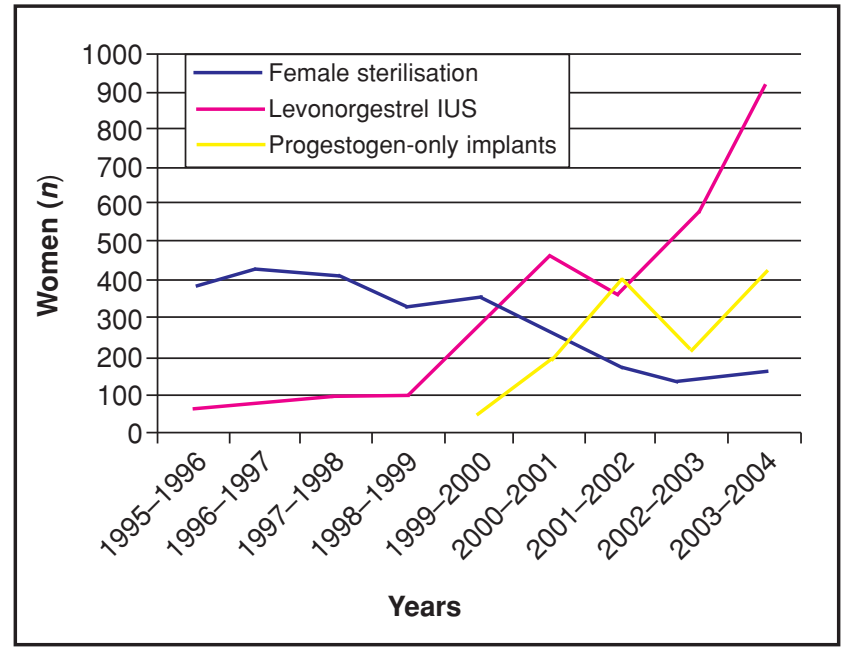

Figure 3 Use of permanent and long-acting reversible contraception in Newcastle women from 1995 until 2004. IUS, intrauterine system 
sterilisation are happy to consider other reversible, effective contraceptive methods that have proven noncontraceptive benefits. Detailed counselling before sterilisation helps to avoid the regret faced by some, ${ }^{2,3}$ with few women and their partners returning within the next 2 years for sterilisation.

Sterilisation is still the most commonly used method of contraception worldwide. ${ }^{4}$ Despite this, the number of endoscopic female sterilisation procedures performed in England and Wales is declining. The total number has fallen by $37.2 \%$ from 47288 in 1998/1999 to 29686 in $2002 / 2003.5$ Over this time the number of female sterilisations performed in the Newcastle area has also declined by $53.4 \%$ (Figure 3 ). We feel that this reduction is due partly to the comprehensive counselling that the women receive in primary and secondary care and partly to the fact that a number of long-term, effective and reversible methods of contraception are now available. Women no longer see sterilisation as the only reliable method of contraception available to them.
Acknowledgements

The authors would like to thank Mr M M Singh and Mrs J Latus for their contribution to this audit.

\section{Statements on funding and competing interests}

Funding. None identified.

Competing interests. Diana Mansour has received lecture fees, financial support for attending conferences and consultancy fees from a number of pharmaceutical companies.

\section{References}

1 Mattinson AB, Mansour D. Female sterilisation: is it what women really want? J Fam Plann Reprod Health Care 2003; 29(3): 136-139.

2 Hillis SD, Marchbanks PA, Tylor LR, Peterson HB. Poststerilization regret: findings from the United States Collaborative Review of Sterilization. Obstet Gynecol 1999; 93: 889-895.

3 Jamieson DJ, Kaufman SC, Costello C, Hillis SD, Marchbanks PA, Peterson HB. A comparison of women's regret after vasectomy versus tubal sterilization. Obstet Gynecol 2002; 1073-1079.

4 Rioux JE, Daris M. Female sterilisation: an update. Curr Opin Gynecol 2000; 13: 377-381.

5 Hospital Episode Statistics: December 1998, December 2002, December 2004. http://www.doh.gov.uk/hes/ [Accessed 4 January 2006].

\section{Book Reviews}

Helping People with Sexual Problems: A Practical Approach for Clinicians. P Trigwell. Oxford, UK: Mosby (Elsevier), 2005. ISBN: 0 7234-3409-3. Price: £15.99. Pages: 108 (paperback)

Sexual problems are common in people attending health services, as they are in the general population; some seek professional help, others would like to. People with sexual difficultie present to a wide range of health care services: Some may present with a direct request for help; others may raise this as a 'parting shot' at the end of a consultation for an unrelated reason. In some cases sexual dysfunction (SD) is detected by sensitive enquiry during consultation for a medical condition with which sexual difficulties may be associated. Service provision for people with SD is, however, variable and insufficient.

Peter Trigwell, a consultant in liaison psychiatry and psychosexual medicine, brings his wealth of clinical experience to this book. His aim is to help the clinician assess his/her patient's SD paying attention to both physical and psychological aspects of the aetiology, to make a formulation and decide upon an appropriate course of action. His practical approach enables the clinician to help those patients for whom provision of relevant information and specific suggestion may obviate the need for referral to specialis services, and to identify those for whom such a referral is indicated.

In this book Dr Trigwell demonstrates the clinical importance of SD and offers an aid to understanding normal sexual functioning, before introducing the reader to the classification of sexual difficulties and their management. The book concentrates on SD as defined in the Diagnostic and Statistical Manual of the American Psychiatric Association (Version IV). It guides the clinician through the assessment of the patien presenting with SD, to identify sexual health need and possible undiagnosed underlying pathology. He describes a general approach to sex therapy and introduces specific techniques used to help people with a range of sexual difficulties including lack of sexual interest, impaired arousal, difficulties with orgasm, sexual pain and vaginismus. A variety of approaches including pharmacological and counselling therapies are introduced. The effects of drugs on sexual function are highlighted. A brief chapter provokes consideration of ethical dilemmas in sexual medicine. The book is well referenced and signposts useful resources for both patient and clinician.

In my opinion, this short book is a usefu resource for the busy clinician who wishes to help patients who present with sexual problems achieve a level of sexual function that is adequate for their sexual needs. Health care professionals from many disciplines will appreciate this accessible and well-written text.

Reviewed by Pippa Green, DFFP, DipPST, Associate Specialist in Sexual Health, Pennine Acute Hospitals NHS Trust, Rochdale, UK

International Handbook of Chlamydia (2nd edn). T R Moss (ed.). Haslemere, UK: Euromed Communications Ltd, 2005. ISBN: 1-8990-15590. Price: $£ 16.95$. Pages: 212 (paperback)

Despite a vast number of publications and its own website, this handbook is a welcome addition to the current knowledge of chlamydia. Revised 5 years after the publication of the first edition, it covers many aspects of chlamydial pathogens whilst focusing on Chlamydia trachomatis.

The book - written by a largely UK-based group of authors - is easy to read and covers topics ranging from diagnosis and clinical manifestations of infection with chlamydia to economic evaluations of screening and control strategies. Most chapters provide an extensive literature review for those interested in more detail.

I think the book would have benefited from a more in-depth update on the natural history and pathogenesis of chlamydia, which in its current format is only covered in fragments in different sections. Conversely, I felt the chapter on 'Is there a role for serology?' was too detailed for a general readership and misleading in its current role and use.

I liked the fact that the book includes chapter on $C$. pneumoniae, trachoma and a clinically useful summary on the causes and management of chronic pelvic pain in young women, although the latter made little reference to the contribution of $C$. trachomatis to this common condition. With the word 'International' in the title, I would also have expected more coverage of the importance of $C$. trachomatis in the context of resource-poor countries, and in particular its synergism with HIV acquisition and transmission and the challenge of its control by screening asymptomatic individuals.

My main criticism has to be of the chapter on 'Chlamydia trachomatis in Fallopian tube disease - the Swedish experience', which includes many assertions and conclusions based on evidence exclusively referenced by publications from the author and includes treatment recommendations that are not recommended practice in national and international guidelines.

Reviewed by Eva Jungmann, MRCP, DFFP, Consultant Physician in GUM/HIV, Camden PCT, London, UK

Sexual Health and the Menopause. J M Tomlinson, M Rees, T Mander (eds). London, UK: The Royal Society of Medicine Press Ltd, 2005. ISBN: 1-8531-5620-5. Price: £12.95. Pages: 80 (paperback)

With advancing age, there is generally a decrease in the frequency of sexual intercourse. However, in modern times, with increasing numbers of failed partnerships, older women may wish to establish new relationships, usually resulting in increased coital frequency.

Published on behalf of the British Menopause Society, this concise text provides useful information to general practitioners, gynaecologists, genitourinary physicians and psychologists who may have to deal with older couples with problems of sexual health.

There are significant contributions that critically review male and female sexual dysfunction, sexually transmitted infections, pharmacotherapy and hormone replacement therapy.

Older women may feel inclined to abandon contraception. An unintended pregnancy at a relatively late age may lead to disastrous consequences. There is a well-written chapter on contraception for perimenopausal women.

Each chapter has a list of relevant references. This small volume is indeed a valuable source of up-to-date information for the management of sexual health problems in the older couple.

Reviewed by $\mathbf{R}$ K Bhathena, FRCOG, FFFP, Consultant Obstetrician and Gynaecologist, Bombay, India 